\title{
Hypertension in children
}

\author{
Mass screening not recommended
}

In adults there are no doubts about the value of treating severe hypertension, ${ }^{1}$ but there are doubts about treating mild hypertension. ${ }^{2}$ The decision on when to begin treatment in children is even more difficult.

Blood pressure rises in children with age $^{3}$ as it does in adults. ${ }^{+}$But the variability of blood pressure in children is greater than in adults, ${ }^{5}$ and therefore regression to the mean, which has bedevilled trials of antihypertensive treatments in adults,${ }^{6}$ is even more of a problem in children. The variability makes familial correlations of blood pressure, though statistically significant, ${ }^{7}$ less relevant clinically. These are the reasons why the British Hypertensive Society ( $p$ 497) and other $\mathrm{s}^{8}$ have been reluctant to recommend mass screening of children, even of those with hypertensive parents. Furthermore, we do not know - as we do for adults - which children will benefit from treatment for hypertension.

Most children with blood pressures above the 95th centile are obese. ${ }^{10}$ Those children who seem to be hypertensive but are simply large for their age may be excluded by assessing blood pressure on the basis of height (see chart on p 497). Obese children who are hypertensive should be advised to lose weight, limit their sodium intake, exercise, and avoid smoking. These recommendations seem harmless and have much to commend them on general health grounds. The concern that further anxiety may be imposed on obese children by labelling them hypertensive may be offset by the educational value of measuring blood pressure.

There are a few children in whom the diagnosis of hypertension is not in doubt, and they must be investigated and treated in specialist units. The blood pressure may have been found to be raised by chance, because of associated illness such as renal disease, or because of symptoms such as failure to thrive, headache, or facial palsy. In an infant of 1 year a systolic blood pressure of $130 \mathrm{~mm} \mathrm{Hg}$ represents severe hypertension, but in older children the blood pressure may be high even by adult criteria. Organs such as the heart, eyes, or kidneys have often been damaged by the time the condition is diagnosed. This severe form of hypertension is nearly always secondary to some other condition - in nine out of 10 cases to renal disease. ${ }^{11}$ Other cases have cardiovascular or endocrine causes.

Renal hypertension is usually caused by parenchymal or renovascular disease but may be associated with renal tumours or chronic renal failure. The most important cause of renal hypertension is pyelonephritic scarring (reflux nephropathy) associated almost exclusively with vesicoureteric reflux and urinary tract infection in early life, but chronic glomerulonephritis is also important. A combination of renal imaging by ultrasonography, radioisotope scanning, or micturating cystourethrography together with measurements of peripheral and renal vein plasma renin and angiography of the renal vein usually suffices to unravel the cause. ${ }^{12}$

Hypertension caused by coarctation of the aorta is associated with a particularly high incidence of heart failure, absent femoral pulses (or a blood pressure that is much higher in the upper than the lower limb), and characteristic radiological and angiographic features. Endocrine causes of hypertension in children are exceptionally rare and include neuroblastoma, phaeochromocytoma, and excess mineralocortoid activity caused by either a tumour or an inborn error of metabolism. Diagnosis depends on recognising associated clinical features, imaging the tumours, and assaying hormones in the blood and urine. Essential hypertension is diagnosed by exclusion, as in adults.

Optimal treatment of these severe forms of hypertension may mean surgical correction or removal of the cause, particularly in renovascular disease. Some endocrine causes of hypertension may be treated medically-for example, spironolactone for certain forms of hyperaldosteronism, or glucocorticoids for congenital adrenal hyperplasia. Conditions that cause excess release of catecholamines may need specific treatment with $\alpha$ and $\beta$ adrenergic blocking agents before an operation. All other causes should be treated with conventional antihypertensive treatment, but it is difficult to know at what blood pressure to start treatment in children. Usually children will be treated if their blood pressure is greatly increased or if they have symptoms or evidence of organ damage. Most antihypertensive drugs that are used in adults have been used in children, but dosages must be related to body size. ${ }^{13}$

Parenteral treatment with intravenous labetalol or sodiuı nitroprusside is the best emergency treatment for hypertension, but sublingual nifedipine is an alternative. ${ }^{14}$ The most common strategy for treating moderate to severe hypertension is a combination of a vasodilator and $\beta$ blocker with or without a diuretic. More resistant hypertension is now treated with angiotensin converting enzyme inhibitors rather than minoxidil as was the case, but calcium channel antagonists are becoming popular second line agents. ${ }^{12} 15$

Nearly all these investigations and treatments are best undertaken by specialists. When resources are scarce we recommend a "best buy" of referral of the few children with 
severe hypertension to tertiary referral centres. We do not recommend mass screening to detect children who may not have hypertension at later measurements and for whom there may be no benefits of detecting mild hypertension. Screening and long term follow up are indicated for children with renal diseases, neurofibromatosis, diabetes mellitus, and probably those with a family history of hypertension, however difficult this may be to define.

Senior Lecturer in Medicine,

M DE SWIET

National Heart and Lung Institute,

London SW3 6LY

Consultant Physician and Paediatric Nephrologist,

Hospital for Sick Children, London WC1N 3JH

1 Veterans Administration Cooperative Study Group on Antihypertensive Agents. A double blind control study of antihspertensive agents. Arch Intern. 11ed 1960;106:133-48.

M J DILLON
Swales JD, Ramsar LE, Coope JR, el al Treating mild hypertension. Br Mled f 1989-248.694-8.

De Swiet M, Favers P. Shinebourne EA. Blood pressure in 4 and 5 vear old children: the effects of environment and other factors in its measurement. The Brompton study. 7 Hypertens 1984;2: $501-5$.

+ Miall WE, Lovell HG. Relation between change of bleod pressure and age. Br.11ed f 1967;ii:660-4. De Swiet M, Fayers P, Shinebourne EA. The value of repeated blood pressure measurements in children - the Brompton study. Br.Med f 1980;280:1567-9.

6 Reader R, Baver GE, Dorle AE, et al. The Australian therapeutic trial in mild hypertension: report by the management committee. Lanct 1980;i:1261-7.

Biron P, Mongeau JG. Familial aggregation of blood pressure and its components. Pediatr Clin North Am 1978:25:29-33

8 Dillon MJ. Blood pressure. Arch Dis Child 1988;63:3+7-9.

9 Hall DMB, ed. Health for all children. A programme for child health surveillance. Oxford: Oxford University Press, 1989.25-6.

10 Voors AW, W'ehber LS, Frerichs RR, Berenson GS. Bodv height and bodv mass as determinants of basal blood pressure in children - the Bogalusa heart study. Am f Eipidemiol 1977;106:101-8.

1 Londe $S$. Cause of hyperion in the young Pediatr Clin North Am 1978:25.55-65.

12 Dillon MJ. Investigation and management of hypertension in children. A personal perspective. Pediatric Nephrology 1987;1:59-68.

3 Dillon MJ. Modern management of hypertension. In: Meadow R, ed. Recent advances in paediatrics. No 7. Edinburgh: Churchill Livingstone, 1984:35-55.

1t Rascher W, Bonzel ILE, Ruder H, Muller-Wiefel DE, Scharer K. Blood pressure and hormonal responses to sublingual nifedipine in acute childhood hypertension. Clin Exp Hypertens [A] $1986 ; 8: 859-69$

15 Portman RJ, Robson A.II. Controversies in paediatric hypertension. In: Tunes BM, Mendoza SA, eds. Pediatric nephrologv. New York: Churchill Livingstone, 1984:265-9.

\title{
The quality divide in primary care
}

\author{
Set to widen under the new contract
}

The evidence for a clear geographical divide in morbidity, mortality, and performance in primary care is consistent and indisputable. ${ }^{1-4}$ Yet it appears from the current debates over the new contract for general practice ${ }^{5}$ and the NHS review ${ }^{6}$ that there is still confusion about the underlying cause.

If disparities in, for example, rates for immunisation and cervical cytology are caused mainly by environmental factors $^{27-10}$ then social action (including subsidies for primary health care) is necessary. If, however, the root cause is the complacency, or even incompetence, of general practitioners in delivering care (failing to organise, computerise, or employ staff) then incentives and penalties are indicated. As the new arrangements in primary care seem to assume that complacency is the problem and that commitment ${ }^{11}$ and organisation ${ }^{12}$ in general practice may override social pressures, high quality evidence in this debate should be warmly welcomed.

In their book Family Doctors and Economic Incentives ${ }^{13}$ Bosanquet and Leese enlarge on previous publications ${ }^{1+15}$ to provide such evidence. The evidence is inevitably complex. They visited 260 practices in six areas of the country chosen for their socioeconomic diversity. These practices were scored on three markers-employing a practice nurse, vocational training, ${ }^{16}$ and using the cost rent scheme-and divided into innovators (two or three markers), intermediate (one marker), or traditional (no marker). Bosanquet and Leese looked for the characteristics, rewards, and penalties for these innovative practices.

The book provides ample evidence that the social milieu of the practice is the key predictor of performance: "Decisions on strategy seemed to be determined mainly by local environment rather than the personal characteristics of the doctors." 13 Practices in deprived areas had less income because of smaller lists (they were less likely to have a rising local population to allow funding through expansion) and fewer partners (and thus higher running costs for each partner). They were more likely to have Asian partners and were much less likely to innovate. Even within a predominantly affluent area such as the Thames valley the urban practices were not innovators. Practices in deprived areas thus have a substantially lower income than practices in more affluent areas and are, not surprisingly, therefore less likely to invest in their practices.
Low investment combined with falling populations leads to reduced income and even less likelihood of investment.

There is, however, also some support for the complacency argument. Regardless of social area the innovating practices are more likely to be larger partnerships, to have a partner who is a member of the Royal College of General Practitioners, and to hold separate baby, antenatal, and well person clinics. As innovating practices are more likely to be well equipped and well staffed this offers some pointers to the behaviour that the profession and the government might wish to encourage. We should remember, however, that larger practices may not always be popular with patients ${ }^{17}$ and that screening may unnecessarily medicalise the healthy. ${ }^{18}$

Although the new contract rewards holding clinics, it removes the group practice allowance. By concentrating substantial funds on attaining high targets it will differentially penalise the practices in deprived areas, and by altering the balance towards capitation fees it will further penalise those practices in areas of static or declining population. The only mitigation, the deprivation supplement to the basic practice allowance, was ill thought out in its original guise, and a new version is awaited. Unless its final form offers substantial rewards the disincentives to investment and innovation in practices in deprived areas will increase under the new contract.

If the Department of Health persists with its current strategy the incentives for vocational trainees to enter practice in socially deprived areas and for existing doctors in these areas to develop their care and services will decline. Rather than following the philosophy that "unto those that hath shall be given," rewards for achievement should relate to the magnitude of the task; otherwise the quality divide will only widen.

Senior Lecturer,

MIKE PRINGLE

Department of General Practice,

Nottingham University Medical School,

Nottingham NH7 2UH

1 Royal Commission on the National Health Service. Report. London: HMSO, 1979.

2 Department of Health and Social Security. Inequalities in health. London: DHSS, 1980. (Black report.

Jarman B. A survey of primary care in London. London: Royal College of General Practitioners, 1981. Occasional paper $\mathrm{No}_{0} 16$ 